\section{A negociação do sexo seguro na TV: discursos de gênero nas falas de agentes comunitárias de saúde do Programa Saúde da Família de Porto Alegre, Rio Grande do Sul, Brasil}

\author{
Safe sex negotiation on TV: gender discourses \\ among female community health workers \\ under the Family Health Program in Porto Alegre, \\ Rio Grande do Sul, Brazil
}

Dora Lúcia Leidens Correa de Oliveira 1 Dagmar Estermann Meyer 2 Luis Henrique Sacchi dos Santos 3 Daniela Montano Wilhelms 4

\footnotetext{
1 Escola de Enfermagem, Universidade Federal do Rio Grande do Sul, Porto Alegre, Brasil.

2 Faculdade de Educação, Universidade Federal do Rio Grande do Sul, Porto Alegre, Brasil. 3 Faculdade de Educação, Universidade Luterana do Brasil, Canoas, Brasil. 4 Núcleo de Epidemiologia, Serviço de Saúde Comunitária, Hospital Nossa Senhora da Conceição, Porto Alegre, Brasil.

Correspondência D. L. L. C. Oliveira Travessa Marrocos 85/301, Porto Alegre, RS 91370-240, Brasil. dora@enf.ufrgs.br
}

\begin{abstract}
This paper analyzes the understanding among female community health workers in the Family Health Program in Porto Alegre, Rio Grande do Sul State, Brazil, concerning the notion of safe sex negotiation promoted by the Brazilian government in AIDS prevention campaigns targeting women. The paper is based on empirical data gathered in 2003. The study focused on TV advertisements used in campaigns by the Brazilian Ministry of Health from 1994 to 2000. The analytical approach was informed by feminist and cultural studies, taken from a post-structuralist and Foucauldian perspective. The research aimed to produce knowledge to support a critical reading of such education for HIVIAIDS prevention, especially concerning gender relations. The paper argues that knowledge and practices permeating the "safe sex negotiation" discourse incorporate, reproduce, and/or transmit hegemonic representations of masculinity and femininity and that these representations differentiate and highlight hierarchical positions of women in relation to men and/or women in relation to other women, producing and/or reinforcing prejudices and inequalities.
\end{abstract}

Safe Sex; Acquired Immunodeficiency Syndrome; Television; Gender

\section{Introdução}

A idéia de que a sexualidade e as práticas sexuais são passíveis de negociação não é nova. O que é novo é o seu reconhecimento público e político como algo positivo. Como diz Barbosa 1 (p. 74), “...se antes essa vinculação estava associada quase que exclusivamente à prostituição, à promiscuidade, à pornografia e, como conseqüência, à doença e à degradação - já que, afinal, quem negocia sexo são as prostitutas, os michês, os cafetões -, nos últimos anos a negociação sexual ganhou o estatuto de algo desejável, positivo e ligado à preservação da saúde". Entendida, inicialmente, como estratégia para a diminuição da transmissão heterossexual do HIV/AIDS, a negociação sexual passa a ter, a partir da constatação da feminização da epidemia 2, uma maior importância na proteção das mulheres contra a infecção pelo HIV. Nas análises das causas do avanço da epidemia entre mulheres enfatiza-se, cada vez mais, que tal avanço tem a ver com as desigualdades de poder que, tradicionalmente, organizam as relações mulheres/homens em todas as dimensões do social.

A emergência do conceito de vulnerabilidade 3,4 , permitindo repensar a questão dos grupos e comportamentos de risco para além de aspectos individuais e enfatizando a importância de uma associação entre fatores coletivos e contextuais, levou ao reposicionamento das 
mulheres no contexto da prevenção. Uma das questões usualmente enfocadas, e que assume nova importância nesse contexto, é a da dificuldade das mulheres para negociar com seus parceiros a adoção de medidas preventivas, pois a camisinha masculina é um método controlado pelos homens. Isto resulta na idéia de que é preciso promover a capacitação das mulheres para a negociação do sexo seguro, capacitação que tem sido, freqüentemente, buscada através de campanhas veiculadas na televisão (vide as análises de Hidelbrand 5, Polistchuck 6 e Santos 7).

$\mathrm{O}$ presente artigo analisa algumas das informações obtidas na pesquisa Educação, Saúde, Gênero e Midia: Um Estudo sobre HIVIAIDSDSTs com Agentes Comunitários/as de Saúde do Programa de Saúde da Família de Porto Alegre/RS, a qual foi financiada com recursos da Coordenação Nacional de DST e AIDS (CN-DST/ AIDS) e da Organização das Nações Unidas para a Educação, a Ciência e a Cultura (UNESCO). A pesquisa teve como foco a análise de alguns dos anúncios televisivos que integraram as campanhas oficiais de prevenção do HIV/AIDS, implementadas pelo Ministério da Saúde (MS) no Brasil, no período de 1994 a 2000 (ver conteúdo dos mesmos em Santos 7).

Na época, em função da descoberta da população feminina como um dos grupos sociais em que mais crescia a infecção pelo HIV, o MS passou a dar prioridade à produção de anúncios televisivos endereçados às mulheres 7. Partindo da discussão de cinco desses anúncios com agentes comunitários de saúde (ACS) do Programa Saúde da Família (PSF) de Porto Alegre, Rio Grande do Sul, Brasil, a pesquisa visava produzir subsídios para uma leitura crítica desse tipo de educação para a prevenção da AIDS, em especial no que se refere às relações de gênero ali representadas. Embora a pesquisa tenha procurado articular AIDS, educação, gênero, saúde e mídia, explorando suas diferentes dimensões, o presente artigo toma como fio condutor e mote de análise, especificamente, a questão da negociação do sexo seguro. A análise, contudo, não se propõe a retomar os principais pontos do debate atual acerca da negociação do sexo seguro, mas, sim, destacar o entendimento das ACS sobre a questão, com base nas suas experiências enquanto mulheres que ocupam uma dupla posição de sujeito: mulheres da comunidade e mulheres agentes de saúde. Neste sentido, a negociação do sexo seguro foi tomada como ponto de partida para a análise de questões que aparecem nos anúncios televisivos endereçados às mulheres, produzidos pelas campanhas governamentais de prevenção ao HIV/AIDS, como traição, monogamia, desigualdade de poder etc. Gênero e identidade são categorias que emergem desta análise como centrais para o entendimento dos anúncios televisivos das campanhas de prevenção ao HIV/AIDS como artefatos culturais implicados na produção e re-produção de representações hegemônicas de masculinidade e feminilidade, que diferenciam e hierarquizam mulheres em relação a homens e/ou diferenciam mulheres de outras mulheres.

\section{Pressupostos teóricos}

As análises produzidas no contexto da pesquisa são informadas pelas vertentes dos estudos feministas e culturais que se aproximam da perspectiva pós-estruturalista de Michel Foucault, sendo embasadas em cinco pressupostos fundamentais. Primeiramente, trabalhamos com uma noção de cultura entendendo-a como um campo de luta e contestação, no qual são produzidos os sentidos e os sujeitos que constituem os diferentes grupos sociais. Em segundo lugar, entendemos a linguagem, em seu sentido lato, como sendo o meio privilegiado pelo qual atribuímos sentido ao mundo e a nós mesmos e que, por isso, ela se constitui como um elemento central da organização social e da cultura. Um terceiro pressuposto enfatiza a educação como um conjunto de processos pelos quais indivíduos são transformados e/ou se transformam em sujeitos de uma cultura. Tornar-se sujeito de uma cultura envolve um complexo de forças e de processos de aprendizagem que, hoje, inclui com especial ênfase, os meios de comunicação de massa, nos quais a TV tem papel de destaque. Um quarto pressuposto é o de que o conceito de representação engloba práticas de significação lingüística e cultural e sistemas simbólicos através dos quais os significados são construídos. E um quinto pressuposto, que enfatiza uma noção de gênero que extrapola a discussão de papéis e funções de mulher e de homem, englobando todas as formas de construção social, cultural e lingüística imbricadas nos processos que diferenciam mulheres de homens ${ }^{8}$. Baseados nesses pressupostos, optamos pela abordagem da análise cultural para descrever e analisar os discursos que constituem as representações que possibilitaram aos/às participantes da pesquisa expressar-se do modo como o fizeram. Na perspectiva foucaultiana, discurso se refere ao conjunto de saberes e práticas "que formam sistematicamente os objetos de que falam" 9 (p. 56). Isto significa dizer que os discursos que estari- 
am supostamente descrevendo um real prédado, estão, de fato, implicados com a produção deste real e de seus sujeitos. A abordagem da análise cultural foi utilizada como estratégia para o re-conhecimento e a descrição de algumas das posições de sujeito que os/as ACS ocupam quando falam deles/as próprios/as e dos / as usuários/as que atendem. Buscamos, também, compreender como e quais discursos acerca da saúde, das DSTs/HIV-AIDS e de formas de viver o gênero e a sexualidade estão implicados na produção dos significados compartilhados nestes grupos sociais. Adotar uma abordagem teórico-metodológica que pressupõe a produção discursiva da cultura e de seus sujeitos não implica, portanto, a negação da existência material de pessoas, coisas e eventos, mas sustentar que tais coisas só significam e se tornam verdadeiras dentro, ou pela articulação, de determinados discursos enraizados em contextos particulares. Argumenta-se, então, que são os discursos (médico, do senso comum, moral etc.) e não um indivíduo (ACS), um programa de saúde (PSF) ou uma instituição social isolada (MS) que os enunciam ou veiculam, que produzem aquilo que re-conhecemos, por exemplo, como modos adequados de viver o gênero em um dado contexto. Os anúncios foram considerados como artefatos pedagógicos que, além de procurarem ensinar modos de prevenção ao HIV/AIDS, pelo uso do preservativo, também incorporam e re-produzem representações de gênero múltiplas, instáveis e conflitantes.

\section{Procedimentos metodológicos}

Para o levantamento das informações que analisamos qualitativamente, utilizamos a técnica de grupo focal, encontro grupal semi-estruturado coordenado por um moderador, realizado em um ambiente informal e que tem como propósito reunir informações sobre um foco específico de interesse do pesquisador 10. A técnica de grupo focal foi considerada particularmente útil, considerando a característica de permitir o compartilhamento de experiências, opiniões, e interesses dos/as seus/suas participantes, dentro do próprio contexto da pesquisa. Coletar dados através de grupos focais tem como vantagens, entre outras, a possibilidade de tornar o espaço da pesquisa agradável para seus participantes e a redução do tempo de coleta. Dentre as desvantagens, estão as dificuldades na transcrição das discussões gravadas e na identificação de quem fala. Uma vez organizada a lista de 24 agentes comunitários/as de saú- de (22 mulheres e 2 homens) que participariam da pesquisa, distribuímos o total de participantes em dois grupos de 12 elementos. Cada participante da pesquisa era vinculado/a a um dos 24 PSFs pertencentes a três Gerências Distritais de Saúde do Município de Porto Alegre e, em sua maioria, trabalhavam há mais de um ano no PSF.

Durante um período de seis semanas, cada grupo participou de um encontro semanal com duas horas de duração, desenvolvido em quatro momentos: apresentação de um anúncio de TV de campanhas de prevenção da AIDS produzidas sob encomenda do MS; análise grupal do anúncio (por exemplo, quanto ao formato visual, conteúdo e linguagem); lanche; retomada das idéias já discutidas e ampliação da discussão para além de questões relacionadas ao vídeo. Para a análise dos dados, contamos com a ajuda do programa Qualitative Solutions Research (QSR) Nvivo 2.0, um programa computacional que se fundamenta no princípio da codificação e armazenamento de textos em categorias específicas, substituindo o tradicional método de operacionalização da análise qualitativa que utiliza recursos como tesoura e cola (para um relato mais completo das possibilidades do uso do QSR Nvivo 2.0 ver Guizzo et al. 11). O programa é ferramenta útil, contudo, apenas na organização dos dados e não substitui o pesquisador na sua análise e interpretação. O projeto de pesquisa foi aprovado pelo Comitê de Ética em Pesquisa da Prefeitura Municipal de Porto Alegre. Cada participante da pesquisa assinou Termo de Consentimento Livre e Esclarecido, tendo sido informado, previamente, sobre objetivos e procedimentos da pesquisa e confidencialidade.

\section{Eu, ela, nós, elas: sexo seguro e conflitos de identidade}

A câmera, focalizando em um ângulo baixo, mostra inicialmente os braços cruzados de uma mulher jovem. Ela tamborila os dedos sobre o braço, num sinal de espera. A câmera sobe lentamente até o seu rosto, mostrando que ela está de olhos fechados. A cena também indica que ela está na penumbra e que talvez, próximo a ela, esteja uma janela cuja cortina se movimenta ao "sabor do vento". A câmera focaliza a atriz em close-up quando esta abre os olhos e dirige o olhar para um ponto "fora" do foco da câmera. O texto dela é narrado em off, como uma negociação "telepática” com o homem. "Ah...usa, vai...tsch! Assim eu vou embora, hein...não vai dar...”. A câmera focaliza rapi- 
damente, em close-up, um homem jovem que devolve o olhar à mulher, mostrando uma expressão de dúvida e de indecisão ao dar de ombros e sorrir. "Pensa bem...”, diz a mulher. Uma caixa em que se lê a palavra "preservativos" é focalizada, em plano de detalhe, tomando quase todo o vídeo. “...A gente se cuidando, juntinhos, super-relaxados... usa, vai”. Enquanto o narrador discorre o texto, "tem horas que uma moça bem comportada tem que virar uma mulher sem vergonha ... de se cuidar e até de dizer não", o homem abre a caixa, retira uma embalagem com um preservativo e o examina fazendo um gesto de consentimento com a cabeça. A câmera focaliza a mulher se deslocando, sorrindo, e se lançando sobre a cama nos braços do homem. "[...] Evite a AIDS, preserve a vida", diz o narrador. Felizes, o homem e a mulher seguram a camisinha. Volta a voz em off da mulher. “Põe a camisinha, põe...”. O narrador lê o slogan da campanha "Quem se ama se cuida" (Decupagem do anúncio Negociação produzido pela Agência Master em 1995, por encomenda do MS 7).

O anúncio acima descrito (por nós denominado Negociação e apresentado na TV brasileira no ano de 1995), fez parte do conjunto de cinco anúncios (Ele na TV, 1995; Você usa camisinha?, 1996; Canções Carnaval, 1999; e Papo, 2000 - todos produzidos no âmbito das políticas de prevenção do MS) que foram discutidos no contexto da pesquisa. Nele se evidencia o foco explícito das campanhas oficiais de prevenção ao HIV/AIDS no processo de negociação que precede o uso da camisinha masculina nas relações heterossexuais e o interesse em mostrar a mulher como condutora desse processo. $\mathrm{O}$ anúncio foi o primeiro a ser apresentado e analisado pelos/as ACS, tendo gerado informações relevantes aos propósitos da pesquisa. Apesar de a negociação do sexo seguro ser uma temática implícita nos conteúdos dos cinco anúncios apresentados, é no anúncio descrito acima que ela aparece com maior destaque.

A maioria das falas utilizadas para ilustrar a análise apresentada no presente artigo constitui, portanto, excertos das discussões estimuladas, em particular, por esse anúncio. Isso não significa dizer que, na análise, tenhamos considerado esses dados isoladamente, inclusive porque houve sempre o cuidado de integrar nas discussões sobre anúncios específicos o que havia sido tratado em outras discussões desenvolvidas no processo de pesquisa. Importante destacar que as falas são apresentadas, aqui, fora do contexto das discussões, em forma de pequenos diálogos e falas isoladas, o que pode contribuir para diminuir ou aumentar seu impacto, ou mesmo, sugerir outras interpretações. Dada a impossibilidade de reproduzir, aqui, todas as falas, esse é um risco que, como pesquisadoras/es, não podemos deixar de assumir.

As categorias sexo seguro e negociação do sexo seguro têm sido recorrentes nas campanhas televisivas, as quais endereçam mensagens aos telespectadores com um forte apelo ao uso da camisinha em $100 \%$ das relações sexuais. Em todos os cinco anúncios que discutimos com os/as ACS, a categoria sexo seguro e a camisinha masculina faziam parte, implícita ou explicitamente, do conteúdo da mensagem transmitida. Considerada a influência da mídia e dos anúncios das campanhas de prevenção na produção dos significados que dão sentido à AIDS 5,12 não é difícil entender porque sexo seguro ganhou destaque nas discussões desenvolvidas no contexto da pesquisa. A importância dada pelos/as ACS às formas de se negociar segurança nas relações heterossexuais, via demanda do uso da camisinha masculina, não foi resultado, contudo, somente do que foi enfatizado nos anúncios, mas, também, da nossa proposta de problematização dos seus conteúdos à luz da noção de gênero.

Apesar de contar com dois homens nos grupos pesquisados, daremos prioridade, aqui, às falas das mulheres participantes da pesquisa. Esta opção se deve, principalmente, à importante posição das mulheres ACS nas equipes do PSF, enquanto educadoras das mulheres da comunidade e, ao mesmo tempo, sujeitos dos discursos da negociação do sexo seguro. Reconhecendo-se como mulheres e, ao mesmo tempo, como profissionais da saúde, as ACS são interpeladas pelos discursos preventivos do HIV/ AIDS em dois níveis: em primeiro lugar como promotoras da saúde das outras, via orientação e incentivo para a demanda do uso da camisinha masculina; e, em segundo, como responsáveis pela sua própria proteção. Alternando posições de sujeito nas suas falas, ora se colocando como mulher falando da sua experiência, ora como agente de saúde, trazendo exemplos das mulheres da comunidade, as ACS nos permitiram explorar, não só, como as mulheres da comunidade se posicionam com relação aos discursos da saúde sobre a negociação do sexo seguro, mas, também, como elas são posicionadas por esses discursos. As falas das ACS expõem os conflitos gerados pelas diferentes posições de sujeito por elas assumidas nos discursos que instituem os significados de sexo seguro como centrais na produção de uma lógica de prevenção. 


\section{Colocando elas no lugar delas: a complexidade da negociação do sexo seguro e as incongruências dos discursos de prevenção ao HIV/AIDS}

Representações naturalizadas de feminino e de masculino atravessam e constituem as falas das ACS. Submissão, fraqueza, passividade, dependência e sentimentalismo, são algumas das características apontadas nas falas das ACS como típicas de mulher: "a mulher é submissa e não tem coragem de chegar para o marido e dizer - olha fulano é para o nosso bem, não tô querendo dizer que tá me traindo, tá tendo relação extra-conjugal, né? Mas só que eu queria, eu gostaria que tu usasse camisinha". Para negociar segurança no sexo a situação da mulher ainda é mais complicada pelo fato de essa ser "muito sentimental" e "mais romântica". Além disso, as mulheres "são muito cômodas", no sentido de que "se contentam com pouca coisa, só porque o homem coloca o arroz e feijão dentro de casa". Nas falas das ACS, feminino e masculino funcionam como oposições binárias, formas discursivas que tradicionalmente informam e/ou constituem os significados e as relações de gênero (e também as mensagens dos anúncios das campanhas de prevenção). Em contraposição às representações de mulher como pessoa fraca, submissa e passiva, as representações de homem se encaixam no padrão de masculinidade legitimado pelo senso comum - força, atividade, dominação, racionalidade: o homem "é mais prático", "é mais objetivo naquilo que ele quer", "é muito mais rápido", "é muito machista...gosta de trair". Representações como essas são constitutivas dos discursos que circulam presentemente no campo da promoção da saúde da mulher, em especial quando o foco é o investimento no sexo seguro.

Assim como nas falas das ACS, a idéia de uma vulnerabilidade feminina generalizada e a desigualdade de poder de gênero que expõe a mulher a riscos são pressupostos que orientam os discursos preventivistas produzidos no contexto das políticas governamentais de prevenção ao HIV/AIDS 2,13. Neste contexto, ganha destaque a noção de empowerment - dar poder a - um investimento que poderia reduzir a vulnerabilidade feminina à infecção pelo HIV. Empowerment engloba nos seus significados a idéia de que existem grupos de indivíduos que se encontram subjugados a outros e precisam ampliar seu poder e capacidade para negociar sua segurança pessoal (nos programas oficiais de prevenção da AIDS, entendida reduzidamente como proteção da saúde) nas suas relações com esses outros. A associação entre $\mathrm{em}$ - powerment e negociação sexual feminina precisa ser vista com cautela, considerando que, como vemos no anúncio descrito acima, essa "sugere possibilidade de soluções individuais e racionais em uma área ainda dominada pelas preferências masculinas" 14 (p. 151).

Como exemplifica o anúncio descrito anteriormente, sexo seguro tem sido representado nessas campanhas como relação sexual com penetração sem riscos de transmissão de DSTs, especialmente, da AIDS. Risco, comportamento sexual saudável e racionalidade individual se encontram fundidas na expressão sexo seguro, que herda as limitações da definição biomédica de risco - probabilidade de dano à saúde - e de sexo - interação sexual entre duas pessoas envolvendo práticas penetrativas 15 . Nessa perspectiva, sexo seguro engloba o problemático atributo de sexo saudável, onde saúde é condição a ser garantida exclusivamente pelo uso da camisinha masculina em todas as relações sexuais.

No caso das relações heterossexuais, temse que, por princípio, a prática do sexo seguro deve conferir segurança à mulher e ao homem. As falas das ACS sobre a situação das mulheres com as quais convivem na comunidade sugere, contudo, que, para essas mulheres, sexo seguro tem mais a ver com outras necessidades mais imediatas de segurança (contra agressões físicas, por exemplo) do que com a ameaça, a longo prazo, do vírus HIV 15,16. Além disso, negociar com o parceiro o uso da camisinha masculina é visto como uma operação, por si só, arriscada, inclusive do ponto de vista dos danos à saúde que a operação pode envolver.

No contexto das comunidades nas quais as ACS moram e trabalham, a pontual meta de prevenção de doenças parece não corresponder às necessidades femininas de proteção em um campo de práticas como o sexual, vivenciado como locus de um portfolio de riscos 15 . Essa idéia de que sexo arriscado/sexo seguro é definido por muitas mulheres em referência a um portfolio de riscos a que elas estão expostas através da atividade sexual e que, estas expressões podem significar, para essas mulheres, mais que simplesmente exposição a - ou proteção contra - infecções sexuais, foi desenvolvida por um de nós 15 , em uma pesquisa sobre como as mulheres adolescentes percebem o risco pessoal de infecção pelo HIV via sexo. Para a pesquisadora, sexo arriscado não se define como esta entidade monolítica de que tratam os discursos oficiais do HIV/AIDS, mas se refere a um conjunto hierarquizado de riscos que são interdependentes em significado e valor. Nessa perspectiva, sexo seguro não pode ser 
garantido, apenas, pelo uso da camisinha masculina, argumento corroborado pelas falas das ACS, onde sexo seguro assume contornos bem mais amplos do que os apresentados nos discursos oficiais de prevenção ao HIV/AIDS. Segundo as ACS, a iniciativa da mulher em negociar com o parceiro o sexo seguro, pode implicar, por exemplo, riscos morais. "Se a mulher insiste em usar [a camisinha] ele diz, bom ela está sendo infiel comigo...ela estaria passando atestado de corno, ou o parceiro pode pensar 'quem sabe aquele filho nem é dele... porque se ela está insistindo...”. Há, também, o risco de o parceiro passar a trair a mulher em resposta à sua negativa em manter relação sexual sem a proteção da camisinha masculina. "Elas querem a camisinha, mas o marido não aceita a camisinha...aí, para não ter traição, elas acabam aceitando a ter relação sem camisinha...ela cede pra não perder o casamento". A negociação sexual também pode resultar em agressão física. Se uma mulher casada pedir ao marido para que esse use a camisinha, ela poderá "chegar no posto com o rosto desse tamanho”. Essas falas sugerem que, para as mulheres da comunidade onde as ACS vivem e trabalham, a negociação sexual pode funcionar num sentido inverso daquele desenhado pelas campanhas de prevenção ao HIV/AIDS endereçadas ao público feminino, expondo-as a riscos mais imediatos e importantes que a própria relação sexual sem camisinha.

Embora as mulheres de que falam as ACS não tenham sido, ainda, infectadas pelo HIV, essas são vistas como suas vítimas potenciais, no sentido de que poderão se tornar soropositivas se continuarem a se expor ao risco da forma como estão presentemente fazendo. Nesse sentido, são mulheres que poderão se tornar, em breve, exemplos de pessoas, as quais, ao contrário das ACS, não administraram adequadamente a segurança da sua vida sexual. Como agentes de saúde e, portanto, responsáveis por fazer circular os discursos da saúde junto aos grupos sociais definidos por esses discursos como necessitados, as ACS investem na produção de uma identidade segura, diferente daquela de mulher vítima e vulnerável. Esse investimento, porém, não segue um caminho linear. Na afirmação das identidades/diferenças - essa sou eu, não ela ou elas - inúmeras características apontadas como típicas da identidade das outras re-aparecem como definidoras da identidade das ACS.

\section{Entre "eu" e "elas"... existe diferença?}

Ocupar o espaço de interlocução entre os discursos da saúde e os discursos do senso comum que instituem e atravessam a cultura da comunidade que atendem no PSF, torna complicado o posicionamento das ACS como mulheres que, como as outras da comunidade em que vivem, estão expostas ao risco do HIV/AIDS. Para as ACS, cuja função é "ajudar a população a se prevenir", fica difícil uma identificação com essas outras - representadas como submissas, fracas, sentimentais e, por isso, incapazes de se proteger contra o risco do HIV/AIDS. A diferenciação entre eu e as outras parece ter, pelo menos, duas vias: uma processada através da afirmativa da capacidade de cuidar de si - eu me cuido significando a consciência do risco e o uso da camisinha - e outra através da negação da necessidade pessoal do auto-cuidado. As falas das ACS sugerem, ainda, que, além de estar relacionado a representações negativas de feminino, esse processo de diferenciação é também informado por representações negativas de masculino. Para as ACS, o risco da infecção sexual da mulher pelo vírus HIV tem a ver com a natureza do homem, um indivíduo que "gosta de trair". Nesse sentido, optar por segurança ao invés de risco, parece incluir a escolha de um parceiro que, ao contrário dos parceiros das outras, seja fiel.

A afirmativa de algumas ACS de que utilizam a camisinha para se proteger contra a ameaça do HIV/AIDS demonstra que a infecção sexual pelo HIV é uma possibilidade considerada: "eu acho que quem tá na chuva é pra se molhar"; "pode acontecer comigo sim, independente de qualquer coisa"; "eu me cuido!". A consciência do risco é afirmada com base no pressuposto da infidelidade masculina ou na idéia de que "todo o homem trai" e que "o homem que não trai já traiu”. A consideração de que todos os homens são, em princípio, traidores, leva à conclusão de que todas as mulheres são vítimas potenciais da infidelidade masculina daí a consciência do risco. O caráter homogeneizador dessas representações de homem e de mulher, semelhantes às que aparecem nos anúncios das campanhas de prevenção do HIV/ AIDS, parece não deixar margem para dúvida sobre a necessidade feminina de proteção, uma lógica que sugere um certo senso de resignação. Homogeneizador, aqui, é usado no sentido de enfatizar uma tendência das abordagens contemporâneas no campo da saúde da mulher em tomar a desvantagem das mulheres nas suas relações com os homens como dada e aplicar a noção de empowerment com o intuito de equalizar estas relações. 
Relatos de experiências pessoais mostram que a consciência do risco advém, muito mais, de saberes práticos e contextualizados do que dos conhecimentos científicos que constituem os discursos da saúde. A ênfase dos discursos oficiais de prevenção ao HIV/AIDS na conscientização das mulheres que têm parceiro fixo, sobre a necessidade de se protegerem contra o HIV/AIDS, gera angústia e dúvida entre as ACS (na sua maioria vivendo relações estáveis), a quem tem sido confiada a importante tarefa de fazer circular no grupo de mulheres com quem trabalham, a idéia de que é imperativo o autocuidado: "no momento que tu vê-eu sou uma dessas mulheres, eu sou uma casada, bah, eu tenho certeza que meu marido é fiel - eu acho que tu pára pra pensar. Pode ser que tu não aja, que tu não vá pedir para ele pôr camisinha, mas tu pára pra pensar" A inevitável e simbólica conexão entre camisinha masculina e infidelidade masculina produzida no contexto dos discursos oficiais de prevenção ao HIV/AIDS é uma barreira para a identificação das ACS como mulheres que precisam se proteger da traição dos seus parceiros. Assumir publicamente um comportamento preventivo pode significar uma declaração pública de que a infidelidade do parceiro é uma possibilidade. Isso é problemático, na medida em que põe em xeque a lealdade e a reciprocidade de sentimentos que, na nossa cultura, devem pautar as relações conjugais estáveis. As falas que seguem expõem os conflitos que resultam de tudo isso e sugerem que, apesar de fazerem parte do cotidiano das ACS, as posições de sujeito disponibilizadas pelos anúncios das campanhas de prevenção ao HIV/AIDS, nem sempre são aceitas sem contestação. Por exemplo, uma das participantes da pesquisa, que é casada, reconhece o risco pessoal de ser infectada numa relação sexual, mas tem dificuldade para aceitar que a origem do risco é a infidelidade do marido: " $e u$ uso [camisinha] não pelo sentido de que ele está me traindo..., eu uso porque é melhor usar, não quer dizer que eu estou usando porque ele está me traindo... eu acho que tem muitos homens que traem e muitas mulheres que não traem. Na dúvida, o melhor é usar". Outra ACS, também casada, faz um relato de uma bem-sucedida negociação que fez com o marido: "eu disse para ele, não tô dizendo que tu vai me trair, mas se tu for me trair pelo menos que seja seguro...faz três anos que eu uso [camisinha] direto".

Processos de diferenciação entre o "eu" e o "outro" estão comumente implicados na produção de sentidos para o HIV/AIDS. Nas primeiras fases da epidemia da AIDS, determinadas categorias sociais ficaram fortemente mar- cadas como grupos de risco (conjunto de pessoas semelhantes entre si e diferentes da população em geral). Embora os profissionais da saúde tenham avançado o seu entendimento sobre o HIV/AIDS, no sentido de reconhecer que esse tipo de categorização não corresponde aos movimentos atuais da epidemia, suas ações preventivas continuam a priorizar determinados grupos sociais - homossexuais, usuários de drogas, adolescentes e mulheres - em detrimento de outros, por exemplo, os homens heterossexuais que não pertencem aos três primeiros grupos. Esse tipo de abordagem tem contribuído para a negação do risco da infecção pelo HIV entre os membros dessa dita $p o$ pulação em geral. Isto vem facilitando definições públicas da epidemia da AIDS como um problema dos outros, não meu ou do meu grupo 17. Como sugerem as abordagens sociológicas do risco em saúde 15,18, essa produção de identidades seguras tem a ver com a forma como risco tem sido definido nos discursos oficiais que tratam da questão da prevenção em saúde em tempos pós-modernos. Atualmente, salvo quando se está tratando de desastres naturais e ambientais, risco em saúde é representado como uma situação de dano potencial que é resultado, principalmente, de fatores individuais. Nesse sentido, se tem argumentado que, na contemporaneidade, correr risco apresenta um certo caráter definidor de identidades desviantes. O desvio estaria na ignorância, fraqueza, falta de interesse no cuidado de si, esse último um imperativo numa sociedade em que se atribui um alto valor à autonomia individual e à competência para o auto-governo 15 .

A saúde pública tem incorporado nos seus discursos a noção de risco enquanto escolha individual. Comportar-se de modo a expor-se ao risco da infecção pelo HIV/AIDS é, conforme os discursos da saúde, moralmente incorreto. Para as ACS, (escolher) correr o risco de se infectar pelo HIV nas suas relações sexuais se constituiria em falta grave e seria complicado justificar com as explicações tradicionalmente disponíveis nos discursos da saúde: no caso da população em geral, falta de informação e/ou incorreta percepção de risco, e com relação especificamente às mulheres, também falta de poder. Como ditam os discursos preventivistas no campo da AIDS, o conhecimento científico sobre o risco deve (ou deveria) ser condição suficiente para a competência e interesse no cuidado de si.

Quando, na nossa análise, destacamos as dificuldades das ACS para se posicionarem como mulheres da comunidade que estão expostas ao risco sexual do HIV/AIDS, não queremos 
afirmar que essas se expressaram seguindo um padrão de compreensão e representação da negociação sexual. Nas discussões grupais, a produção de uma linguagem de consenso é, muitas vezes, interrompida por falas que expressam idéias contrárias ao consenso que vêm se delineando. Há momentos em que a análise da situação das outras mulheres estimula a reflexão sobre a própria experiência com relação à negociação do sexo seguro, expondo os conflitos entre as posições de sujeito ocupadas pelas ACS. Por exemplo, a opinião de uma ACS de que " a guria tem que ter iniciativa [a de ter a camisinha na bolsa]", é seguida da fala de outra que diz: "às vezes a gente não pode pregar as coisas que nem a gente mesma coloca em prática”.

A experiência de viver identidades múltiplas que podem ser conflitantes, como as de mulher da comunidade e ACS, resulta da combinação de uma multiplicidade de discursos ou elementos de discurso que, em suas falas e relatos, são acionados tomando como referência distintas representações do "eu" e das "outras". Assim como as mulheres da comunidade são apresentadas como diferentes entre si - a que se cuida, a que não se cuida, a que é submissa, a que é acomodada etc. - porém, em geral tratadas nas falas como "ela" ou "a mulher", também as ACS falam de si como pessoas distintas. Isso, sem se desvincular, totalmente, de uma identidade de grupo - "a maioria de nós é casa$d a$ " - que, ao fim e ao cabo, confere a diferenciação necessária (entre "eu, mulher ACS" e "ela, mulher da comunidade") para garantir uma certa relativização da norma veiculada pelas campanhas de prevenção que apresentam a vulnerabilidade feminina ao HIV/AIDS como absoluta.

\section{Eu, nós e elas: identidades que fazem diferença em tempos de AIDS}

Os sistemas de representação, ao construírem lugares que nos posicionam ou, ao proporcionarem respostas que nos possibilitam entender aquilo que somos, constróem posições de sujeito, produzem identidades. Como afirma Silva 19 (p. 46), “a identidade cultural ou social é o conjunto daquelas características pelas quais os grupos sociais se definem como grupos: aquilo que eles são. Aquilo que eles são, entretanto, é inseparável daquilo que eles não são, daquelas características que os fazem diferentes de outros grupos". O autor segue argumentando que os processos de produção lingüística da identidade e da diferença, bem como os processos de produção cultural e social da identidade e da diferença, estão estreitamente relacionados e que esta produção se dá, em grande parte, nos (e através dos) sistemas de representação social. Os sistemas de representação, em conexão com o poder que opera na linguagem, estão envolvidos de forma fundamental com aquilo que nós somos e nos tornamos 19. As falas das ACS expressam alguns dos modos pelos quais esses processos de diferenciação funcionam. Nas suas análises sobre a situação das mulheres, enquanto sujeitos do risco de infecção sexual pelo HIV, elas re-conheceram inúmeros pontos de conflito entre os conteúdos dos anúncios das campanhas de prevenção ao HIV/AIDS, a elas apresentados, e o que elas reconhecem como realidade. Com base nessas análises foi possível delinear alguns desses movimentos de diferenciação entre as mulheres da comunidade e as ACS. Nesses movimentos emergiram, também, relatos e reflexões sobre o próprio estatuto de vulnerabilidade das ACS e suas condições para escapar dele ou modificá-lo. Ou seja, para falar de vulnerabilidade feminina ao HIV/AIDS, foi preciso, também, falar de si, enquanto mulher e profissional da saúde, identidades que também não são fixas, estáveis ou, necessariamente, convergentes.

Não é por acaso que, durante os grupos focais, as ACS se expressaram, inúmeras vezes, usando uma linguagem que é própria dos discursos da saúde - janela imunológica, anti-retrovirais, soropositividade (termos que, em geral, não fazem parte do vocabulário das pessoas de sua comunidade) - provavelmente aprendida nos cursos de capacitação dos quais foram alunas no âmbito do PSF. Em suas falas, esses termos operam como demarcadores de identidades que fazem diferença quando a problemática da feminização da epidemia da AIDS e a quase onipresença do risco para as mulheres é considerada. No entanto, as fronteiras que delimitam a diferença são tênues e provisórias. As contradições e os conflitos emergem quando, para falar de si, as ACS lançam mão de uma linguagem aprendida nas experiências cotidianas de que são sujeitos na comunidade. As desigualdades de poder de gênero, as características (tidas como típicas) de homens e de mulheres da comunidade, o contexto social desfavorável, e outros, são elementos discursivos que atravessam, na mesma medida, as representações de "eu" e de "outra", quando se passa a fazer parte da comunidade. Nesse sentido, considerando-se os desafios que nos são colocados hoje pela epidemia do HIV/AIDS, as falas das ACS acerca da negociação do sexo seguro indicam que as formas pelas quais se delimitam lugares, se posicionam sujeitos e se 
demarcam fronteiras com base no jogo diferença/identidade que esse discurso institui, são cruciais de serem entendidas se queremos investir, tanto na compreensão de sua historicidade e especificidade, quanto num deslocamento destes limites e lugares. Como profissionais da saúde e da educação, preocupados com estas questões, deveríamos, então, nos perguntar o quanto os conhecimentos, práticas e instituições envolvidos com a prevenção ao HIV/ AIDS estão implicados, não só com a prevenção ou o seu tratamento, mas, também, com processos de diferenciação de gênero e sexualidade. Desde essa perspectiva, pensamos que estudos como este nos instigam a questionar o quanto, e como, conhecimentos e práticas que circunscrevem o campo da saúde incorporam, re-produzem ou veiculam representações hegemônicas de masculinidade e feminilidade (por exemplo, nos discursos do empowerment e da negociação do sexo seguro). Podemos questionar, ainda, de que forma estas representações diferenciam e hierarquizam mulheres em

\section{Resumo}

O artigo analisa, com base numa pesquisa realizada no ano de 2003, o entendimento de agentes comunitárias de saúde do Programa Saúde da Família de Porto Alegre, Rio Grande do Sul, Brasil, sobre a noção de "negociação de sexo seguro" veiculada nas campanhas de prevenção à AIDS que são endereçados às mulheres. A pesquisa tinha como foco de análise alguns dos anúncios televisivos que integraram as campanhas implementadas pelo Ministério da Saúde no Brasil, no período de 1994 a 2000. A análise foi informada pelas vertentes dos estudos feministas e culturais que se aproximam da perspectiva pós-estruturalista de Michel Foucault e tinha como objetivo produzir subsídios para uma leitura crítica desse tipo de estratégia educativa para a prevenção da AIDS, em especial no que se refere às relações de gênero ali representadas. A análise das informações sugere que os conhecimentos e práticas que circunscrevem o discurso da negociação do sexo seguro incorporam, re-produzem ou veiculam representações hegemônicas de masculinidade e feminilidade e que estas diferenciam e hierarquizam mulheres em relação aos homens e/ou diferenciam mulheres de outras mulheres, produzindo elou reforçando preconceitos e desigualdades.

Sexo Seguro; Síndrome de Imunodeficiência Adquirida; Televisão; Gênero relação aos homens e/ou diferenciam mulheres de outras mulheres, produzindo e/ou reforçando exclusões e desigualdades.

As ACS ocupam uma posição central no PSF, porque se supõe que elas possam estabelecer uma mediação entre os saberes biomédicos e as mulheres de suas comunidades. Considerando a ambigüidade de tal mediação, e baseados na análise aqui apresentada, recomendamos que as instâncias governamentais que produzem os anúncios televisivos das campanhas de prevenção ao HIV/AIDS e propõem estratégias de capacitação das equipes de saúde, desenvolvam ações educativas que incorporem os saberes que estes indivíduos vivenciam em suas comunidades. Acreditamos que isto poderá contribuir para o tensionamento dos saberes biomédicos, de modo que os/as integrantes das equipes de saúde sejam capazes de fazer frente à complexidade das questões associadas à problemática da AIDS, posto que eles/elas são importantes agentes destas ações.

\section{Colaboradores}

Todos os co-autores fizeram parte da equipe que desenvolveu a pesquisa e a análise dos dados que deu origem ao artigo. A pesquisa, intitulada Educação, Saúde, Gênero e Mídia, foi coordenada por D. E. Meyer. Especificamente com relação à redação do artigo, D. L. L. C. Oliveira, como autora principal, coordenou a sua elaboração, propondo e desenvolvendo os argumentos que deveriam compor o texto. As idéias desenvolvidas foram discutidas, incrementadas, complementadas e/ou reformuladas em reuniões do grupo de co-autores. Ao final, a produção do texto teve a participação de todo o grupo, embora o formato final tenha sido completado por D. L. L. C. Oliveira. 


\section{Referências}

1. Barbosa RM. Negociação sexual ou sexo negociado? Poder, gênero e sexualidade em tempos de AIDS. In: Barbosa RM, Parker R, organizadores. Sexualidades pelo avesso: direitos, identidades e poder. São Paulo: Editora 34; 1999. p. 73-88.

2. Bastos FI. A feminização da epidemia de AIDS no Brasil: determinantes estruturais e alternativas de enfrentamento. Rio de Janeiro: Associação Brasileira Interdisciplinar de AIDS; 2001. (Coleção ABIA: Saúde Sexual e Reprodutiva 3).

3. Mann J, Tarantola DJM, Netter TW, organizadores. A AIDS no mundo. Rio de Janeiro: RelumeDumará/Associação Brasileira Interdisciplinar de AIDS/Instituto de Medicina Social, Universidade do Estado do Rio de Janeiro; 1993.

4. Ayres JRCM. Vulnerabilidade e prevenção em tempos de AIDS. In: Barbosa RM, Parker R, organizadores. Sexualidades pelo avesso: direitos, identidades e poder. São Paulo: Editora 34; 1999. p. 49-72.

5. Hidelbrand L. Comunicação oficial brasileira sobre a AIDS: um percurso pelas linhas e entrelinhas da telinha da TV [Tese de Doutorado]. São Paulo: Universidade de São Paulo; 1995.

6. Polistchuck I. Campanhas de saúde pela televisão: campanha de AIDS da Rede Globo [Dissertação de Mestrado]. Rio de Janeiro: Escola de Comunicação, Universidade Federal do Rio de Janeiro; 1999.

7. Santos LHS. Biopolíticas de HIV/AIDS no Brasil: uma análise dos anúncios televisivos das campanhas oficiais de prevenção (1986-2000) [Tese de Doutorado]. Porto Alegre: Faculdade de Educação, Universidade Federal do Rio Grande do Sul; 2002.

8. Meyer D, Oliveira DL, Santos LHS, Wilhelms DM Educação, saúde, gênero e mídia: um estudo sobre HIV/AIDS-DSTs com agentes comunitários/ as de saúde do Programa de Saúde da Família em Porto Alegre, RS. Porto Alegre: Faculdade de Educação, Universidade Federal do Rio Grande do Sul; 2003.
9. Foucault M. Arqueologia do saber. Rio de Janeiro: Forense Universitária; 1987.

10. Carey MA. The group effect in focus group: planning, implementing and interpreting focus group research. In: Morse JM, editor. Critical issues in qualitative research methods. London: Sage Publications; 1994. p. 225-41.

11. Guizzo B, Oliveira DL, Krziminski C. O software QSR Nvivo 2.0 na análise qualitativa de dados: ferramentas para a pesquisa em ciências humanas e da saúde. Rev Gaúch Enferm 2003; 24:53-60.

12. Weelings K, Field B. Stopping AIDS - AIDS/HIV public education and the mass media in Europe. London: Longman; 1996.

13. Guimarães CD. AIDS no feminino: por que cada dia mais mulheres contraem AIDS no Brasil? Rio de Janeiro: Editora UFRJ; 2001.

14. Giffin K. Beyond empowerment: heterosexualities and the prevention of AIDS. Soc Sci Med 1998; 46:151-6.

15. Oliveira D. Adolescent women talk about HIV/ AIDS risk: reconceptualizing risky sex - What implications for health promotion? [PhD Thesis]. London: Institute of Education, University of London; 2001.

16. Heilborn ML, Gouveia PF. “Marido é tudo igual”: mulheres populares e sexualidade no contexto da AIDS. In: Barbosa RM, Parker R, organizadores. Sexualidades pelo avesso: direitos, identidades e poder. São Paulo: Editora 34; 1999. p. 175-98.

17. Schiller NG, Crystal S, Lewellen D. Risky business: the cultural construction of AIDS risk groups. Soc Sci Med 1994; 38:1337-46.

18. Lupton D. The imperative of health: public health and the regulated body. London: Sage Publications; 1995.

19. Silva TT. O currículo como fetiche: a política e a poética do texto curricular. Belo Horizonte: Autêntica; 1999.

Recebido em 18/Nov/2003

Versão final reapresentada em 27/Abr/2004 Aprovado em 10/Mai/2004 